\title{
Photosynthetic compensation of non-leaf organ stems of the invasive species Sphagneticola trilobata (L.) Pruski at low temperature
}

\author{
Min-ling Cai ${ }^{1}$. Wen-qiao Ding ${ }^{1}$ Jun-jie Zhai ${ }^{1} \cdot$ Xiao-ting Zheng $^{1} \cdot$ Zheng-chao Yu $^{1} \cdot$ Qi-lei Zhang ${ }^{1} \cdot$ Xiao-hua Lin $^{1}$. \\ Wah Soon $\mathrm{Chow}^{2} \cdot$ Chang-lian Peng ${ }^{1}$ (1)
}

Received: 6 February 2020 / Accepted: 7 April 2020

○) Springer Nature B.V. 2020

\begin{abstract}
Biological invasion is a hot topic in ecological research. Most studies on the physiological mechanisms of plants focus on leaves, but few studies focus on stems. To study the tolerance of invasive plant (Sphagneticola trilobata L.) to low temperature, relevant physiological indicators (including anthocyanin and chlorophyll) in different organs (leaves and stems) were analyzed, using a native species (Sphagneticola calendulacea L.) as the control. The results showed that, upon exposure to low temperature for 15 days, the stems of two Sphagneticola species were markedly reddened, their anthocyanin content increased, chlorophyll and chlorophyll fluorescence parameters decreased, and the accumulation of reactive oxygen species in the stem increased. The percentage increases of antioxidants and total antioxidant capacities in stems were significantly higher in S. trilobata than in S. calendulacea. This showed that $S$. trilobata had higher cold tolerance in stems while leaves were opposite. To further verify the higher cold tolerance of the stem of $S$. trilobata, a defoliation experiment was designed. We found that the defoliated stem of S. trilobata reduced anthocyanin accumulation and increased chlorophyll content, while alleviating membrane lipid damage and electrical conductivity, and the defoliated stem still showed an increase in stem diameter and biomass under low temperature. The discovery of the physiological and adaptive mechanisms of the stem of $S$. trilobata to low temperature will provide a theoretical basis for explaining how $S$. trilobata maintains its annual growth in South China. This is of great significance for predicting the future spread of cloned and propagated invasive plants.
\end{abstract}

Keywords Sphagneticola trilobata (L.) pruski · Stem · Photosynthesis · Anthocyanin

\begin{tabular}{|c|c|c|}
\hline \multicolumn{3}{|c|}{ Abbreviations } \\
\hline \multicolumn{2}{|c|}{ Chl $a(b)$} & Chlorophyll $a(b)$ \\
\hline \multicolumn{2}{|c|}{ Chl } & Total chlorophyll \\
\hline \multicolumn{2}{|c|}{ DAB } & Diaminobenzidine \\
\hline \multicolumn{2}{|c|}{ DPPH } & 1,1-Diphenyl-2-picrylhydrazyl \\
\hline \multicolumn{2}{|c|}{ ETR } & Electron transport rate \\
\hline \multicolumn{2}{|c|}{$F_{0}$} & Minimum fluorescence \\
\hline \multicolumn{2}{|c|}{$F_{\mathrm{m}}$} & $\begin{array}{l}\text { Maximum fluorescence yield of the dark- } \\
\text { adapted state }\end{array}$ \\
\hline \ & \multicolumn{2}{|c|}{$\begin{array}{l}\text { Chang-lian Peng } \\
\text { pengchl@ @scib.ac.cn }\end{array}$} \\
\hline 1 & \multicolumn{2}{|c|}{$\begin{array}{l}\text { Guangdong Provincial Key Laboratory of Biotechnology } \\
\text { for Plant Development, Guangzhou Key Laboratory } \\
\text { of Subtropical Biodiversity and Biomonitoring, College } \\
\text { of Life Sciences, South China Normal University, } \\
\text { Guangzhou 510631, China }\end{array}$} \\
\hline 2 & \multicolumn{2}{|c|}{$\begin{array}{l}\text { Division of Plant Science, Research School of Biology, } \\
\text { College of Science, The Australian National University, } \\
\text { Acton, ACT 2601, Australia }\end{array}$} \\
\hline
\end{tabular}

Abbreviations

Chl $a(b) \quad$ Chlorophyll $a(b)$

Chl Total chlorophyll

DAB Diaminobenzidine

DPPH 1,1-Diphenyl-2-picrylhydrazyl

ETR Electron transport rate

$F_{0} \quad$ Minimum fluorescence

adapted state 
species. Research shows that many exotic organisms have successfully invaded China (Huang et al. 2009; Wang et al. 2003). These invasive species not only threaten the diversity of organisms and change the structure and function of ecosystems but also bring huge economic losses to the invaded areas (Early et al. 2016).

Previous studies have shown that phenotypic plasticity, genetic differentiation, lack of natural enemies, and allelopathy are important mechanisms for successful invasion by invasive species (Gioria and Osborne 2014). Among them, phenotypic plasticity is the main method to address the variation in environmental factors (Fusco and Minelli 2010). When limited resources are available for plant organs, trade-offs occur. In unusual environmental conditions, these trade-offs cause species to distribute widely and cause plants to have different characteristics in different environments (Tuller et al. 2018). However, a close relationship has been found between interorgan resource trade-offs and phenotypic plasticity. At present, there are two different adaptive responses in plants under different environmental conditions: (1) simultaneous traits optimization and (2) dynamic traits changes to adapt to prevailing conditions. This phenomenon is called phenotypic plasticity (Xiao and Dean 2016). Phenotypic plasticity has been thought to promote biological invasion. It ensures that a species can maintain appropriate ecological and physiological performance in a novel environment. Species that exhibit phenotypic plasticity have better adaptability to different light levels, temperature conditions, and soil nutrient conditions in the invasion areas. For example, Mikania micrantha produces a large number of light seeds and had a rapid reproductive capacity (Shen et al. 2016), and Ipomoea cairica adapts well to changing water availability by changing its allelopathy and biomass allocation patterns (Takao et al. 2011). Studies have demonstrated that the phenotypic plasticity of plants is often closely related to the trade-offs in the allocation of resources among organs (Murren et al. 2015). When limited resources are allocated to different morphological characteristics, the increase in one characteristic leads to the decrease in another, and this trade-off in the allocation of resources is an important driver of plant phenotypic plasticity (Gratani 2014). The trade-off phenomenon is widespread and takes different forms in different environments. For example, changes in aboveground biomass (Loeser et al. 2004), resource allocation (Wang et al. 2016), and reproductive strategy generally appeared after defoliation (Ida et al. 2012). In a previous study, $M$. micrantha redistributed nutrients and preferentially distributed newly synthesized substances from the roots to the aboveground parts, which compensated for the loss of leaf photosynthetic organs ( $\mathrm{Li}$ et al. 2013). Ambrosia artemisiifolia and Pennisetum centrasiaticum preferentially transfer underground resources to aboveground parts, increasing aboveground biomass by reducing the root-shoot ratio (Gard et al. 2013). Therefore, biologists believe that invasive plants are usually exposed to various environmental conditions and that their successful invasion is associated with rapid ecological differentiation, which might be due to their having greater phenotypic plasticity than native species (Davidson et al. 2011). Because plasticity of physiological and morphological characteristics provides more ways to cope with limited resources, invasive species might benefit from plasticity in low-resource or variable environments. Phenotypic plasticity is a major mechanism by which plant becomes invasive species.

Sphagneticola trilobata (L.) Pruski (Asteraceae), a widespread invasive species in South China, is native to tropical America. Compared with the local species Sphagneticola calendulacea (L.) Pruski, the leaves of S. trilobata can better adapt to low-light environment by improving their $\mathrm{CO}_{2}$ fixation ability and quantum efficiency of light utilization (Song et al. 2010; Sun et al. 2015). In a water-limited environment, S. trilobata can reduce the cost of leaf construction (Song et al. 2009). In addition, the leaves of $S$. trilobata can affect the soil microbial community structure by producing allelochemicals, thus inhibiting the growth of surrounding plants and leading to a successful invasion (Coats and Rumpho 2014). Under high-temperature, highlight condition in summer, the leaves of $S$. trilobata turn obviously red and adapt to the oxidative environment by accumulating a large content of anthocyanins (Feild et al. 2001; Zhang et al. 2012a). As leaf is the most important organ for photosynthesis, it is a sensitive organ during plant evolution. Hitherto, research on the invasion mechanism of S. trilobata has mainly focused on the phenotypic plasticity of leaves in adverse conditions. However, defoliation is a common phenomenon throughout life history of plants. In some adverse condition, plant leaves will wilt and wither. Some non-leaf organs, such as stems, play an important role in maintaining normal plant development (Yang et al 2006). At present, few studies have reported on the phenotypic plasticity of non-photosynthetic organ stems of invasive plants in different environments, and most of these studies have focused on crops (Wang et al. 2001).

Sphagneticola trilobata prefers hot and humid environments. Its pollen vigor and stigma receptivity are poor. There have been no reports on its seed germination. S. trilobata mainly reproduces asexually, and its stem segment is highly plastic. It can expand rapidly through cutting, stripping, and soilless cultivation, and rapidly expands its invasion area throughout the year. In terms of life history, S. trilobata and S. calendulacea are distributed in a mosaic pattern along riverbanks and coastal wet zones in South China. Investigations have shown that compared with S. trilobata, S. calendulacea has higher cold tolerance, and its distribution area could extend from the southern subtropical zone to the temperate zone (Sun et al. 2015). South China is affected by the 
subtropical monsoon climate and has distinct dry and wet seasons. Summer is hot and humid, while winter is cold and cloudy. From the latter half of winter to the onset of the rainy season, low temperature is common. Many subtropical plants are thus impacted by low-temperature conditions. Sun et al. (2015) showed that the tolerance of the leaves of S. trilobata is not as high as that of native species under extremely low temperatures, and the leaves of the invasive plant show chlorosis and wilting.

However, S. trilobata grows rapidly throughout the year in South China. Some studies have found that S. trilobata has the potential to continue to spread to inland regions of China. At present, it is also distributed in Jiangsu, Chongqing, and other regions (Liu et al. 2013). It is unclear how this spread is related to the phenotypic plasticity of the stem at low temperature, and whether using this strategy to cope with a low-temperature environment helps $S$. trilobata spread to temperate regions, thus threatening the survival of the existing distribution of $S$. calendulacea. Therefore, the physiological and ecological characteristics and adaptive mechanisms of the stem of S. trilobata were studied under a low temperature. This study is profoundly significant for predicting the future trends in the clonal propagation of invasive plants and adopting effective management methods.

\section{Material and methods}

\section{Material culture and treatment}

Sphagneticola trilobata and $S$. calendulacea are widely distributed in the riparian, coastal, and other humid environments of the subtropics in China. In this study, plant material was collected from the campus of South China Normal University, Guangzhou, China ( $23^{\circ} 08^{\prime} 47.90^{\prime \prime} \mathrm{N}$, $113^{\circ} 21^{\prime} 15.32^{\prime \prime}$ E). S. trilobata and S. calendulacea were identified according to previous reports performed by our laboratories or other researchers (Sun et al. 2015; Wu et al. 2013). In addition, the materials involved in this study were deposited at the Herbarium of the South China Botanical Garden (IBSC) with the deposition number 806,219 for $S$. trilobata (L). Pruski and 806,217 for S. calendulacea (L). Pruski. Cut shoots with buds were propagated in an incubator (light intensity $100-120 \mu \mathrm{mol} \mathrm{m} \mathrm{m}^{-2} \mathrm{~s}^{-1}$, culture temperature $28 / 25^{\circ} \mathrm{C}$, day/night). After rooting, the regenerated seedlings with approximately the same size and height were selected and transplanted into pots, with 3 plants per pot. When the length of the stem reached $20-30 \mathrm{~cm}$, the plants were used for the experiments.

To compare the tolerance of different organs (leaves and stems) of the plant species to low temperature, the two species cultured at room temperature were moved to a low-temperature culture room $\left(15 \pm 1^{\circ} \mathrm{C}\right)$ (the average temperature in winter in South China is approximately $15{ }^{\circ} \mathrm{C}$ ) for 15 days. Leaves and stems at the third to fifteenth leaf positions were selected as experimental materials on the days 0 and 15 of treatment. To further verify the compensatory effect of plant stems at low temperature, a defoliated experiment was designed. Plants cultured at room temperature were transplanted to a low-temperature culture room $\left(15 \pm 1{ }^{\circ} \mathrm{C}\right)$ for 15 days. Among them, 1/2 of the subjects were randomly chosen for defoliation treatment, while the remaining $1 / 2$ of the plants were not defoliated as control. Stems at the third to fifth leaf positions were chosen as experimental materials on days 0 and 15 of treatment, respectively.

\section{Determination of chlorophyll fluorescence parameters}

The chlorophyll fluorescence parameters of $S$. trilobata and $S$. calendulacea were measured using a chlorophyll fluorescence imaging system (CF Imager, Technological Ltd. Colchester, UK) at low temperatures. Five 8-mm leaf discs and five 1-cm stem segments were placed in 12-well plates (each hole was filled with water), respectively. The leaf discs and stem segments were dark-adapted for 20 min prior to fluorescence determination. The minimum fluorescence $\left(F_{\mathrm{o}}\right)$ was determined with measuring light less than $0.05 \mu \mathrm{mol} \mathrm{m}{ }^{-2} \mathrm{~s}^{-1}$. The maximum fluorescence $\left(F_{\mathrm{m}}\right)$ was induced by a 1-s pulse of saturating light $\left[6162 \mu \mathrm{mol} \mathrm{m}^{-2} \mathrm{~s}^{-1}\right.$ ]. The maximal quantum yield of PSII photochemistry $\left(F_{\mathrm{v}} / F_{\mathrm{m}}\right)$ was calculated as $\left(F_{\mathrm{m}}-F_{\mathrm{o}}\right) / F_{\mathrm{m}}$ (Oxborough and Baker 1997). Subsequently, the steady-state fluorescence $\left(F_{\mathrm{s}}\right)$ and maximum fluorescence $\left(F_{\mathrm{m}}{ }^{\prime}\right)$ were recorded under $400 \mu \mathrm{mol} \mathrm{m} \mathrm{m}^{-2} \mathrm{~s}^{-1}$ actinic light. The actual quantum yield of PSII ( $\left.\Phi_{\mathrm{PSII}}\right)$ and the electron transport rate (ETR) were calculated according to Genty et al. (1989). The formulas were as follows: $\Phi_{\mathrm{PSII}}=\left(F_{\mathrm{m}}{ }^{\prime}-F_{\mathrm{s}}\right) / F_{\mathrm{m}}{ }^{\prime}, \mathrm{ETR}=\Phi_{\mathrm{PSII}}$ $\times$ PPFD $\times 0.5 \times 0.85$.

\section{Anthocyanin content determination}

Leaves $(0.05 \mathrm{~g})$ and stems $(0.05 \mathrm{~g})$ were soaked in $2 \mathrm{~mL} 1 \%$ $\mathrm{HCl}-\mathrm{methanol}(\mathrm{v} / \mathrm{v})$ for $6 \mathrm{~h}$ in darkness. To remove chlorophyll, $1 \mathrm{~mL}$ chloroform and $0.5 \mathrm{~mL}$ pure water were added to a $1-\mathrm{mL}$ extract. After being fully mixed, the solution separated into two layers: chlorophyll was dissolved in the lower chloroform phase, and anthocyanin was dissolved in the upper methanol-water phase. The volume of the upper solution was measured, and the absorption value at $530 \mathrm{~nm}$ was determined using a UV-Vis 2450 spectrophotometer (Shimadzu, Tokyo, Japan). The anthocyanin content in the leaves and stems was calculated using cyanidin-3-O-glucose as a standard curve $(5-200 \mu \mathrm{M})$. 


\section{Determination of chlorophyll content}

Leaves $(0.05 \mathrm{~g})$ and stems $(0.05 \mathrm{~g})$ were placed in $10 \mathrm{~mL}$ centrifuge tubes. They were quickly crushed with metal rods, and liquid nitrogen was added. Then $4 \mathrm{~mL} 80 \%$ acetone solution was added; the tube was shaken well, the cap was tightened, and the solution was extracted overnight at $4{ }^{\circ} \mathrm{C}$. The absorbance of the extract was determined at $663 \mathrm{~nm}$ and $645 \mathrm{~nm}$ using a UV-Vis 2450 spectrophotometer, and $80 \%$ acetone was used as a blank control. The contents of chlorophyll $a$ (Chl $a$ ), chlorophyll $b(\mathrm{Chl} b)$, and total chlorophyll (Chl) were calculated according to Wellburn (1994).

\section{Localization of reactive oxygen species in tissue}

\section{Chemical localization and detection of hydrogen peroxide}

After a low-temperature treatment for 15 days, leaf and stem segments (approximately $2-3 \mathrm{~cm}$ ) were immersed in a dish containing $0.5 \mathrm{mg} \mathrm{mL}^{-1}$ diaminobenzidine (DAB) (using $\mathrm{pH} 7.0$ phosphate buffer as solvent), covered with gauze for $15 \mathrm{~min}$, and then placed in darkness for more than $8 \mathrm{~h}$. The accumulation of ROS could be observed as brown spots after DAB staining. Subsequently, the stained leaves and stems were boiled in 95\% ethanol to remove chlorophyll (Liu et al. 2014). Finally, pictures were taken with a camera.

\section{Chemical localization and detection of superoxide anions}

After 15 days of low-temperature treatment, leaves and stems (approximately 2-3 cm) were immersed in glass dishes containing $0.1 \%$ nitroblue tetrazolium (NBT) and $10 \mathrm{mmol} \mathrm{L}^{-1}$ sodium azide (using pH 6.4 phosphate buffer as solvent). The gauze was vacuum-covered for $15 \mathrm{~min}$ and then placed in darkness for more than $2 \mathrm{~h}$. The samples were monitored for the appearance of indigo blue spots. The chlorophyll was removed by bleaching the sample in a boiled ethanol solution $(95 \%$, v/v) (Sim et al. 2006). Finally, pictures were taken with a camera.

\section{Determination of antioxidants}

The leaves and stems were weighed at $0.05 \mathrm{~g}$, ground with $2 \mathrm{~mL} \mathrm{95 \%} \mathrm{methanol} \mathrm{(v/v),} \mathrm{and} \mathrm{centrifuged} \mathrm{at} \mathrm{13,000} \mathrm{rpm}$ at $4{ }^{\circ} \mathrm{C}$ for $10 \mathrm{~min}$. The supernatant was used to determine the antioxidant indexes such as those of flavonoids and total phenols.

\section{Determination of flavonoid content}

The sample solution was diluted 8 times by the addition of $2 \mathrm{~mL}$ to $200 \mathrm{~mL} 5 \% \mathrm{NaNO}_{2}, 300 \mathrm{~mL} 10 \% \mathrm{AlCl}_{3}$, and $1 \mathrm{~mL}$ of $1 \mathrm{~mol} \mathrm{~L}^{-1} \mathrm{NaOH}$ in turn. After mixing completely, the absorbance value was determined at $510 \mathrm{~nm}$. The standard curve of catechins $\left(25-1000 \mathrm{~mol} \mathrm{~L}^{-1}\right)$ was established to calculate the total flavonoids in the samples.

\section{Determination of total phenol content}

The supernatant $(800 \mu \mathrm{L})$ was diluted with $1 \mathrm{~mL}$ of $95 \%$ methanol, $1 \mathrm{~mL} 10 \%$ Folin phenol reagent, and $2 \mathrm{~mL}$ of $0.7 \mathrm{~mol} \mathrm{~L}^{-1} \mathrm{Na}_{2} \mathrm{CO}_{3}$. Upon mixing, the solution changed color at room temperature. The absorbance at $765 \mathrm{~nm}$ was determined. The standard curve was established with gallic acid $\left(25-250 \mathrm{~mol} \mathrm{~L}^{-1}\right)$, and the content of absolute phenol was calculated.

\section{Determination of DPPH scavenging capacity}

DPPH (1,1-diphenyl-2-picrylhydrazyl) solution $(120 \mu \mathrm{mol}$ $\mathrm{L}^{-1}$ ) was prepared with $95 \%$ methanol. The absorbance at $517 \mathrm{~nm}$ was determined by adding $3 \mathrm{~mL} \mathrm{DPPH}$ solution to $150 \mu \mathrm{L}$ sample solution, with $95 \%$ methanol as a blank control. The standard curve was established by gradient dilution of the DPPH solution $\left(10-120 \mu \mathrm{mol} \mathrm{L}^{-1}\right)$, and the DPPH scavenging capacity of the sample was calculated.

\section{Determination of stem diameter and biomass}

\section{Determination of stem diameter}

During the low-temperature treatment, vernier calipers were used to measure the diameter of plant stem segments (with the second internode as the criterion). Five replicates were used to record the length of the stem diameter at 0 day and 15 days, respectively.

\section{Determination of stem biomass}

The stems of plants were harvested after days 0 and 15 of low-temperature treatment and then packed into different envelopes. The stem was dried to a constant weight in an oven at $75^{\circ} \mathrm{C}$, and the dry weight was measured. The experiment was replicated five times.

\section{Determination of membrane destruction in cells}

\section{Malondialdehyde (MDA)}

Stem segments of $0.1 \mathrm{~g}$ were weighed, and $2 \mathrm{~mL} 10 \%$ trichloroacetic acid (TCA) was added to grind the homogenate. Then they were transferred to $2 \mathrm{~mL}$ centrifuge tubes and centrifuged for $10 \mathrm{~min}$ at $4000 \mathrm{rpm} .1 \mathrm{~mL}$ supernatant was moved to a new centrifugal tube and placed on ice for testing. $1 \mathrm{~mL} 0.6 \%$ thiobarbituric acid (TBA) was added to each centrifuge tube, mixed well, and boiled in a boiling water bath for $30 \mathrm{~min}$. 
It was then cooled quickly on ice. The absorbance values of the supernatant after reaction were determined at 532, 600, and $450 \mathrm{~nm}$ wavelengths. The MDA contents were calculated using the formula: $\mathrm{C}_{\mathrm{MDA}}\left(\mathrm{mol} \mathrm{L}^{-1}\right)=6.45 \times\left(\mathrm{OD}_{532}-\mathrm{OD}_{600}\right)$ $-0.56 \times \mathrm{OD}_{450}$.

\section{Electrolyte permeability}

Two stem segments $(1 \mathrm{~cm})$ were placed in a centrifuge tube filled with $3 \mathrm{~mL}$ superfluous water and then placed in a test tube filled with $10 \mathrm{~mL}$ double-steamed water. After standing at room temperature for $3 \mathrm{~h}$, the electrical conductivity of the exudate in $R_{1}$ was measured by a conductivity meter (PP-15-P11, Sartorius, Germany). Then, the test tube was kept in a boiling water bath for $45 \mathrm{~min}$ to kill living tissues. After cooling to room temperature, the conductivity in $\mathrm{R}_{2}$ was measured by the abovementioned method expressed as the relative conductivity $(\%)$. The leakage rate of the plasma membrane was calculated as $R_{1} / R_{2}$. The experiment was replicated five times.

\section{Statistical analysis}

The data represent the means \pm standard error (SE) of five samples in the experiment. The statistical analysis and multiple data comparisons were performed using IBM SPSS Statistics 19.0 (IBM, NY, USA). Duncan multiple comparison method was used to test the significance of the differences among groups, and differences were considered significant at $p<0.05$. Figures were constructed using SigmaPlot 12.5 (Systat Software, San Jose, CA, USA).

\section{Results}

\section{Comparisons of the tolerance of leaves and stems of two Sphagneticola species under low temperature}

\section{Changes in the phenotype of two Sphagneticola species}

After 15 days of low-temperature treatment, the leaves of both Sphagneticola species showed partial but not obvious reddening that was mainly concentrated at the base of the leaves. The leaves of $S$. trilobata also showed a yellowing phenomenon. Interestingly, though the stems of both Sphagneticola species showed significant reddening, the S. trilobata stems after 15 days of low-temperature treatment were much redder than the native species (Fig. 1).

\section{Changes in the non-photosynthetic pigments and photosynthetic pigments in two Sphagneticola species}

Anthocyanin is a non-photosynthetic pigment. Under the low-temperature treatment, the leaves and stems of both

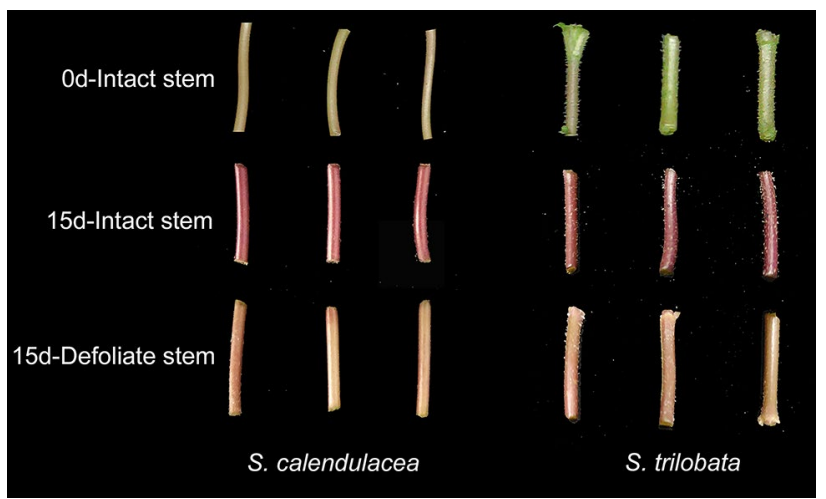

Fig. 1 The stem phenotype of Sphagneticola after different treatments. The picture shows the phenotypic changes in the stems of two Sphagneticola species (0-day intact stem, 15-day intact stem) after a low-temperature treatment for 0 and 15 days. To further study the compensatory effect in the stem, the phenotypic changes in intact and defoliated stems of Sphagneticola were compared after 15 days of low temperatures (15-intact stem and 15-defoliated stem) $(n=5)$

Sphagneticola species turned red due to the accumulation of anthocyanins. In the leaves, the anthocyanin accumulation increased by $205 \%$ and $251 \%$ in the native and invasive species, respectively, which were similar increases (Fig. 2a). However, in the stems, anthocyanin accumulation was nearly 8 times higher in S. trilobata (310\%) than in S. calendulacea (43\%) (Fig. 2b). These results are consistent with the stem reddening in $S$. trilobata being significantly higher than in S. calendulacea (Fig. 1).

Chlorophyll is an important photosynthetic pigment. In the leaves of $S$. calendulacea, $\mathrm{Chl} a, \mathrm{Chl} b$ and $\mathrm{Chl}$ all increased under 15 days of low temperature. In contrast, the content of the photosynthetic pigments in the leaves of S. trilobata decreased under treatment (Fig. 2c, e, g). In addition, the photosynthetic pigments in the stems were decreased in the two Sphagneticola species. Among them, the decreases in Chl $a$ and $\mathrm{Chl} b$ content in S. trilobata were slightly smaller than those in $S$. calendulacea (Fig. 2d, f), and the decrease in total chlorophyll pigment content was also smaller (39\%), at nearly $3 / 4$ of that in the native plants (52\%) (Fig. 2h).

\section{Changes in the chlorophyll fluorescence parameters of the two Sphagneticola species}

At low temperature, the $F_{\mathrm{v}} / F_{\mathrm{m}}$ of the leaves of both Sphagneticola species decreased with the prolongation of the low-temperature treatment. The decrease was $11.60 \%$ in $S$. trilobata, which was 3 times that in S. calendulacea $(4.06 \%)$ (Fig. 3a). The $F_{\mathrm{v}} / F_{\mathrm{m}}$ of the stems of the two plants also had the same downward trend as the leaves. However, the decline rate of $S$. calendulacea was $8.18 \%$, nearly twice that of $S$. trilobata (4.32\%) (Fig. 3b). The $\Phi_{\mathrm{PSII}}$ and ETR can reflect 

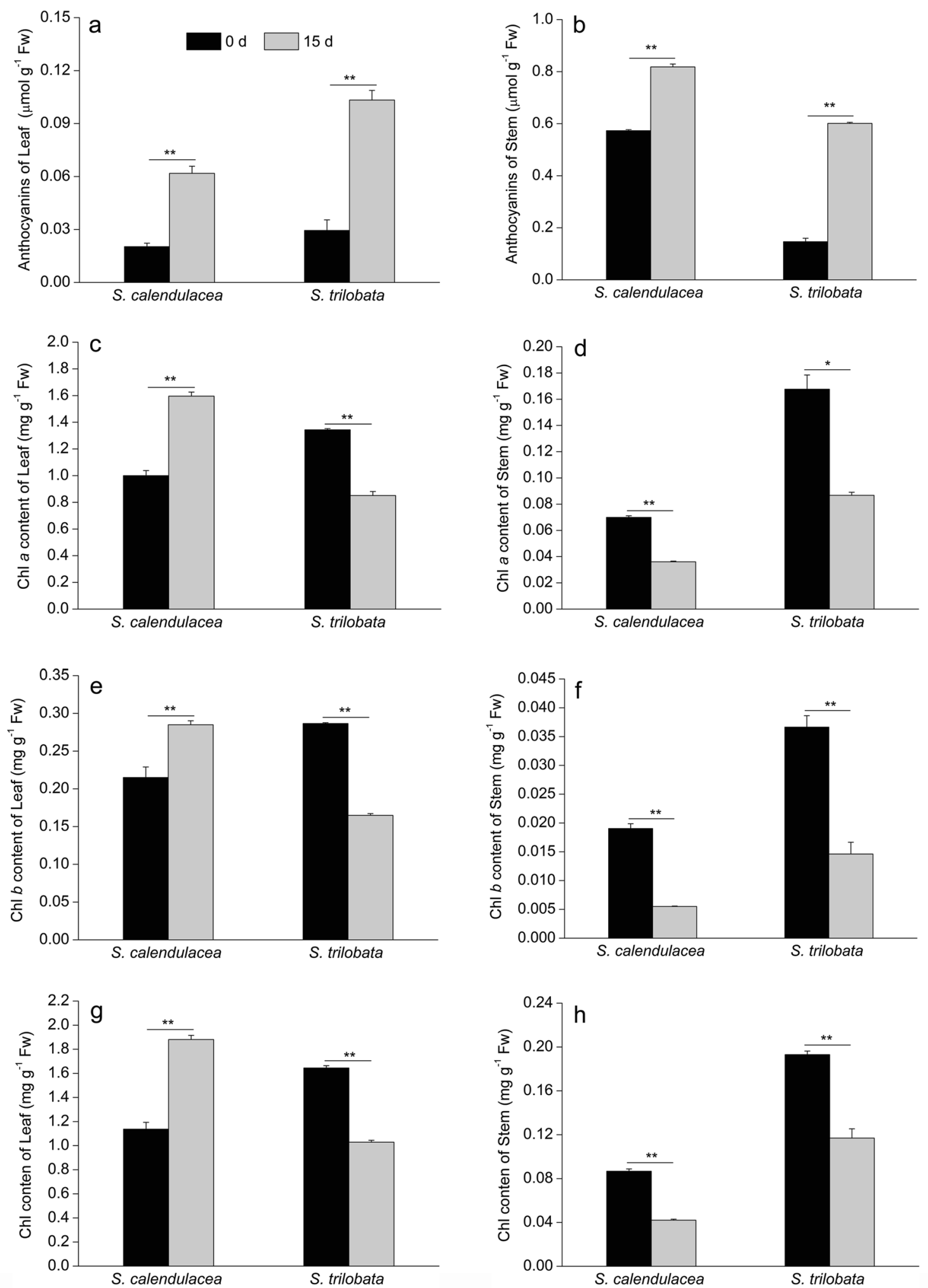

Fig. 2 Changes in anthocyanin and photosynthetic pigments in the leaves and stems of two Sphagneticola species at low temperature. Panels $\mathbf{a}$ and $\mathbf{b}$ represent the changes in the anthocyanin contents of leaves and stems, Panels $\mathbf{c}$ and $\mathbf{d}$ represent the changes in the $\mathrm{Chl} a$ contents in leaves and stems, Panels e and $\mathbf{f}$ represent the changes

in the Chl $b$ contents, and Panels $\mathbf{g}$ and $\mathbf{h}$ represent the changes in total Chl content in leaves and stems $(n=5)$. * indicates a significant difference between 0 and 15 days after low-temperature treatment $(0.01<p<0.05)$; **indicates an extremely significant difference between 0 and 15 days after low-temperature treatment $(p<0.01)$ 
the activity of PSII, and related to the photosynthetic rate of plants. The results showed that the leaves and stems in $\Phi_{\mathrm{PSII}}$ and ETR of the two plant species showed downward trends under the low-temperature treatment. The leaf in $\Phi_{\mathrm{PSII}}$ of S. calendulacea $(1.96 \%)$ was less than that of $S$. trilobata (3.58\%) while the stem in $\Phi_{\mathrm{PSII}}$ of $S$. calendulacea $(10.32 \%)$ was larger than that of S. trilobata (6.41\%) (Fig. 3c, d). Similarly, the changes in the ETR of the leaves and stems of the
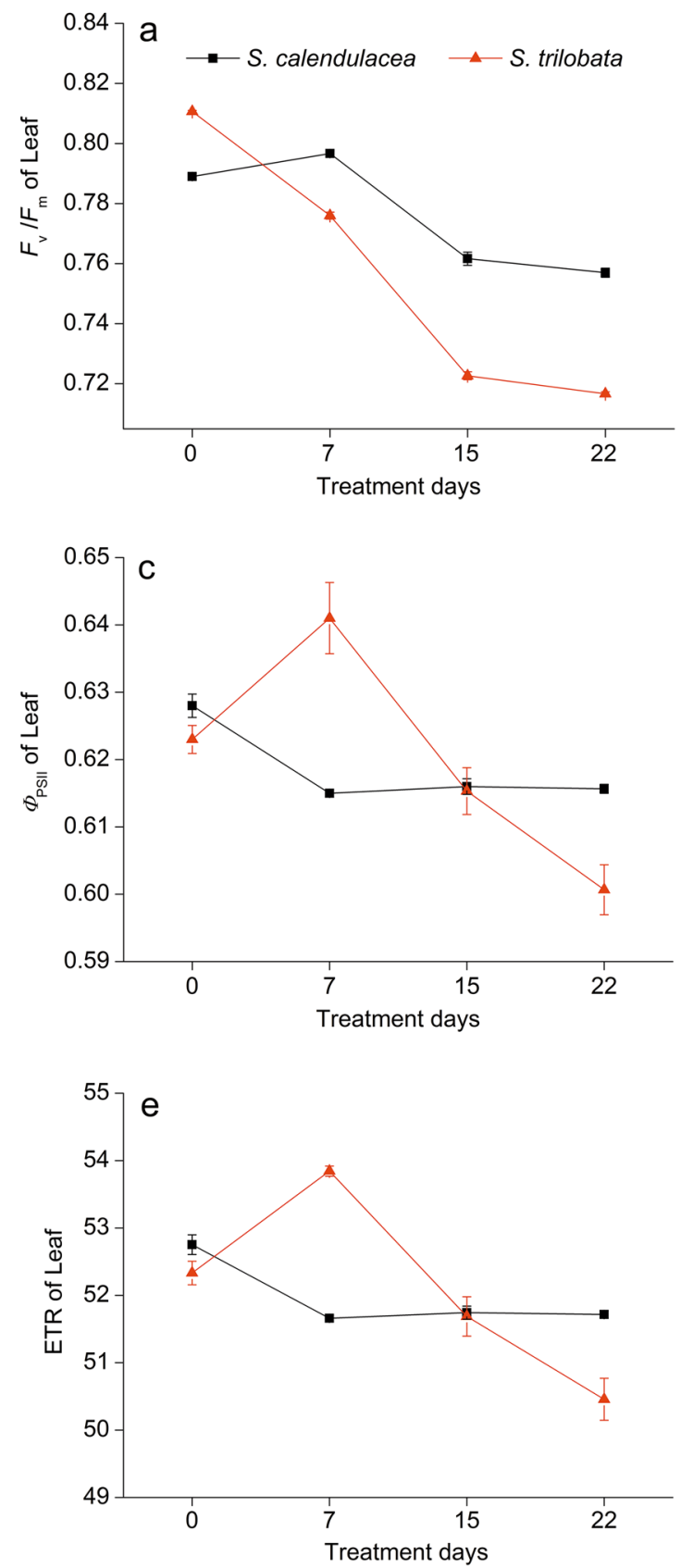

Fig. 3 Chlorophyll fluorescence parameters of leaves and stems from two Sphagneticola species at low temperature with time. Panels a and $\mathbf{b}$ represent the trends of maximal quantum yield of PSII photochemistry $\left(F_{\mathrm{v}} / F_{\mathrm{m}}\right)$ of leaves and stems of the two Sphagneticola spe- two plant species at low temperatures had the same trend as that in $\Phi_{\text {PSII }}$ (Fig. 3e, f).

\section{Localization of reactive oxygen species in the two Sphagneticola species}

Generally, low temperatures lead to excess light energy not being utilized by photosynthesis, and a large amount of
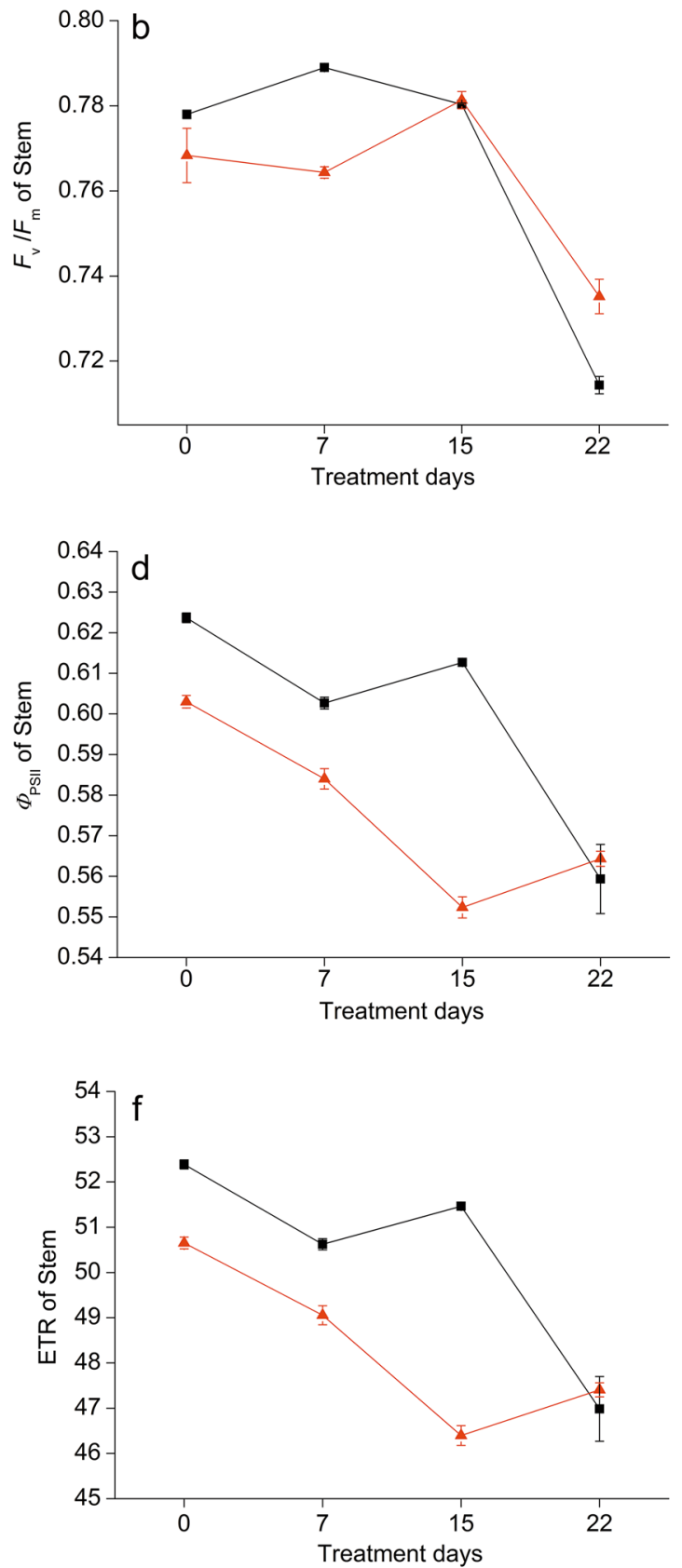

cies; Panels $\mathbf{c}$ and $\mathbf{d}$ represent the trends in the actual quantum yield of PSII ( $\left.\Phi_{\text {PSII }}\right)$ of leaves and stems; and Panels e and $\mathbf{f}$ represent the trends in the electron transfer rate (ETR) of leaves and stems, respectively $(n=5)$ 
reactive oxygen species accumulates in the tissues (Soengas et al. 2018). In this study, the localization of reactive oxygen species (ROS) in the tissue showed that both leaves and stems had accumulated ROS under low temperature, including superoxide anion (Fig. 4a) and hydrogen peroxide (Fig. 4b), The accumulation of ROS in the leaves of $S$. trilobata was higher than that in native plants. In contrast, the accumulation of ROS in the stem of S. trilobata, which mainly occurred at the top and bottom ends of the stem segments, was less than that in S. calendulacea stem.

\section{Changes in antioxidant contents in the two Sphagneticola species}

Normally, the active oxygen scavenging system in plants maintains a balanced presence of ROS. However, changes in the external environment (e.g., low temperature) can lead to the accumulation of ROS in plants. Some studies have shown that ROS could be removed by increasing antioxidant activity (Xu et al. 2017). Consistent with this, the present study found that the antioxidant substances increased in the leaves and stems of S. trilobata and S. calendulacea under lowtemperature treatment. The antioxidant substances, including flavonoids and total phenols in the leaves of S. trilobata, increased less than those in the native plants (Fig. 5a, c). In contrast, the antioxidant substances in the stems increased more in S. trilobata (Fig. 5b, d). The increase in total antioxidant capacity of the leaves of S. trilobata $(245 \%)$ was less than that of the native leaves (298\%) (Fig. 5e), but the increase in the total antioxidant capacity (546\%) of the S. trilobata stems was nearly twice as much as that of the native species stems (258\%) (Fig. 5f).

S. calendulaces

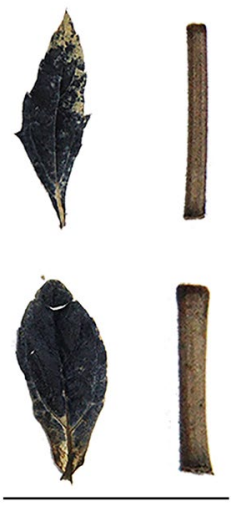

NBT staining $\left(\cdot \mathrm{O}_{2}^{-}\right)$

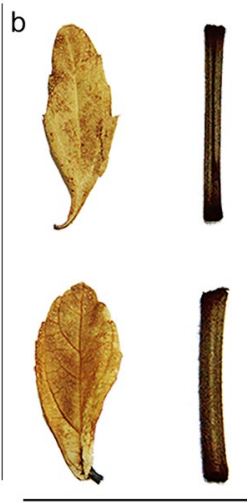

DAB staining $\left(\mathrm{H}_{2} \mathrm{O}_{2}\right)$
Fig. 4 The accumulation of reactive oxygen species (ROS) in the leaves and stems of two Sphagneticola species under low temperatures. Panel a shows the changes in superoxide anion $\left(\cdot \mathrm{O}_{2}^{-}\right)$in the leaves and stems of the two Sphagneticola species after NBT staining. Panel b shows the changes in hydrogen peroxide $\left(\mathrm{H}_{2} \mathrm{O}_{2}\right)$ in the leaves and stems of the two Sphagneticola species after DAB staining

\section{Photosynthetic compensation in the stems of the two Sphagneticola species under low temperature}

\section{Phenotypic changes in the intact and defoliated stems}

To further study the photosynthetic compensatory effect of the stem of $S$. trilobata under low temperature, a defoliation experiment was conducted. Compared to the 0-day treatment, the stems of the two Sphagneticola species had turned red after 15 days of low-temperature treatment. The defoliated stems of S. trilobata and S. calendulacea showed a decrease in redness compared to the intact stem. The phenotypic changes were the most noticeable in S. trilobata (Fig. 1).

\section{Changes in photosynthetic pigments and non-photosynthetic pigments in the intact and defoliated stems}

Pigments in plant tissues are mainly classified into two categories: photosynthetic pigments, such as chlorophyll, and non-photosynthetic pigments, which are mainly anthocyanins. Compared to that at 0 -day treatment, the anthocyanin content of the intact and defoliated stems increased in both Sphagneticola species. S. trilobata had the smallest increase in anthocyanin in the defoliated stem (317\%) (Fig. 6a). There were different trends in chlorophyll content in the two species. Compared to that at 0-day treatment, $\mathrm{Chl} a$ content decreased in the stems of the two Sphagneticola species under low temperature and the lowest decrease in content was observed in the defoliated stem of S. trilobata (13\%) (Fig. 6b). Interestingly, in contrast to the intact stems, the contents of Chl $b$ and $\mathrm{Chl}$ in the defoliated stem of S. trilobata were increased by $35 \%$ and $16 \%$, respectively. The $\mathrm{Chl} b$ contents of $S$. calendulacea were also increased in the defoliated stems, while total $\mathrm{Chl}$ were decreased under low temperature (Fig. 6c, d).

\section{Changes in the degree of cell membrane lipid damage in the intact and defoliated stems}

Malondialdehyde (MDA), the final product of membrane lipid peroxidation, and cell membrane permeability are reliable indicators of cell membrane damage (Ellouzi et al. 2011). When MDA content and cell membrane permeability increase, the cell membrane damage is serious, probably due to excessive free radical accumulation. Compared to 0-day treatment, the MDA content in the intact and defoliated stems of the two Sphagneticola species increased, while the percent increase in MDA content in the defoliated stem of S. trilobata was smallest after 15-day low-temperature treatment (Fig. 7a). Similarly, relative membrane leakage showed 

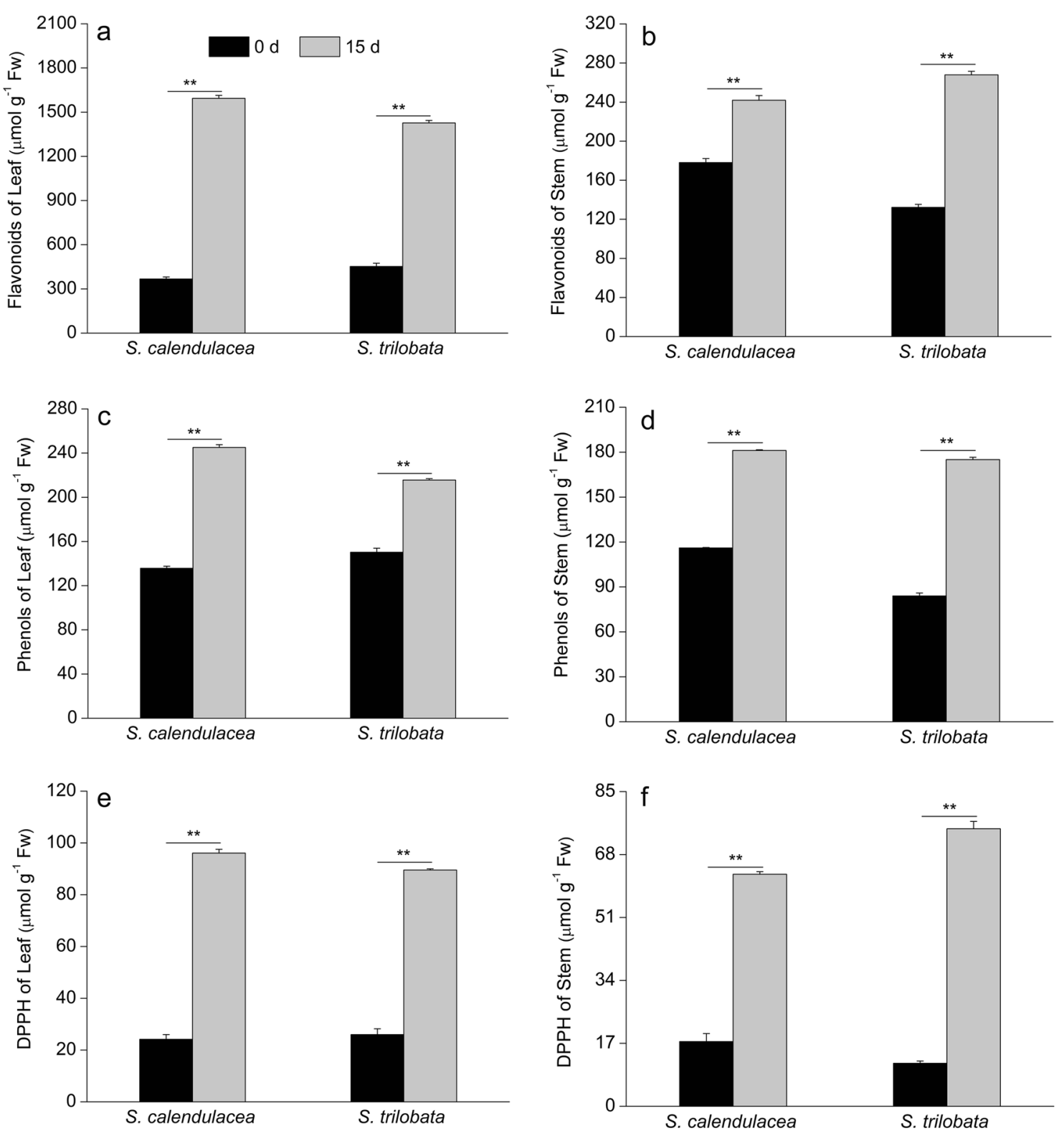

Fig. 5 Changes in antioxidant substance contents in the leaves and stems of two Sphagneticola species under low temperatures. Panels $\mathbf{a}$ and $\mathbf{b}$ show the changes in flavonoid content in the leaves and stems of the two Sphagneticola species. Panels $\mathbf{c}$ and $\mathbf{d}$ show the changes in total phenol content in the leaves and stems of the two Sphagneticola

species. Panels e and $\mathbf{f}$ show the changes in total antioxidant capacity in the leaves and stems, respectively $(n=5)$.**indicates an extremely significant difference between 0 and 15 days after low-temperature treatment $(p<0.01)$

a consistent trend. The percent increase in relative membrane leakage in the defoliated stem of S. trilobata was only approximately 1/11 that in the native plant stems (Fig. 7b).

\section{Changes in the basic indicators in the intact and defoliated stems.}

In this study, we further measured the basic physiological indicators of the stem. The results showed that the diameter and total biomass of the stem increased in both

Sphagneticola species compared to those at the start of treatment. The defoliated stem diameters of $S$. trilobata and S. calendulacea increased by $10.38 \%$ and $8.32 \%$, respectively (Fig. 8a). The percent increase in the total biomass of $S$. trilobata was more than 13 times that of $S$. calendulacea (Fig. 8b). 

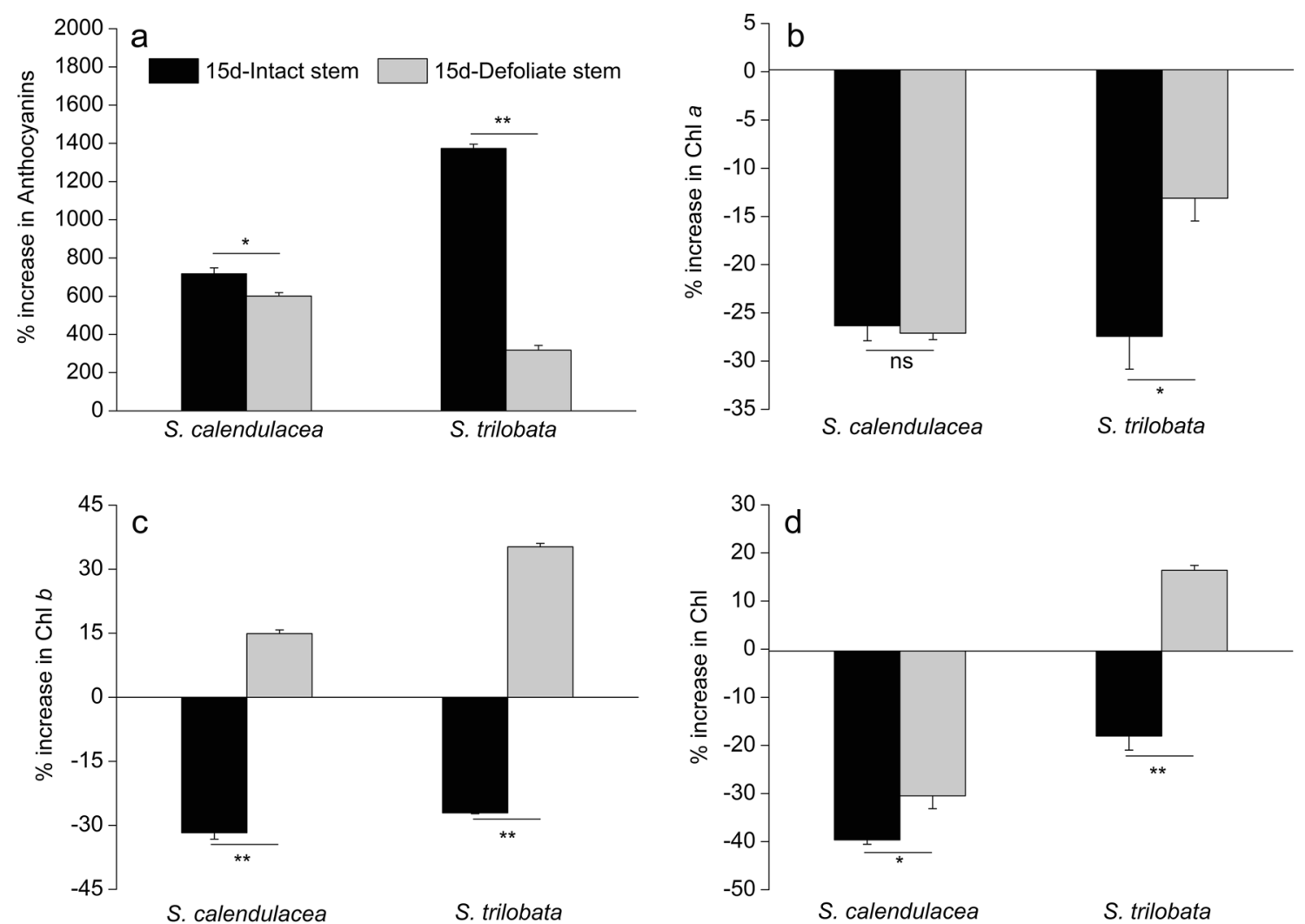

Fig. 6 The \% increase in anthocyanin and photosynthetic pigments in the intact and defoliated stems of two Sphagneticola species under low temperature. Panel a represents the \% increase in anthocyanin in stems after 15-day low-temperature treatment compared to that at 0 day. Panel $\mathbf{b}$ represents the $\%$ increase in Chl $a$ in stems after 15 days of low-temperature treatment compared to that at 0 day. Panel c represents the \% increase in $\mathrm{Chl} b$ in stems after 15 days of low-

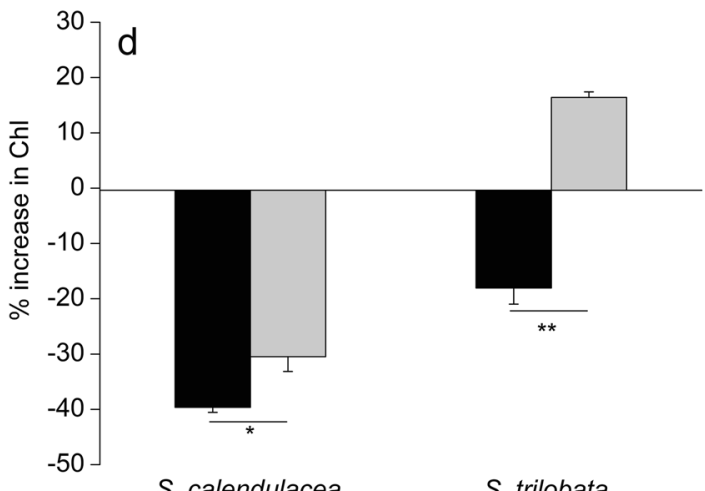

S. calendulacea $\quad$ S. trilobata

temperature treatment compared to that at 0 day. Panel $\mathbf{d}$ shows the $\%$ increase in $\mathrm{Chl}$ in stems after 15 days of low-temperature treatment compared to that at 0 day. * indicates a significant difference between intact and defoliated stems after low-temperature treatment $(0.01<p<0.05)$; ** indicates an extremely significant difference between intact and defoliated stems after low-temperature treatment $(p<0.01)(n=5)$
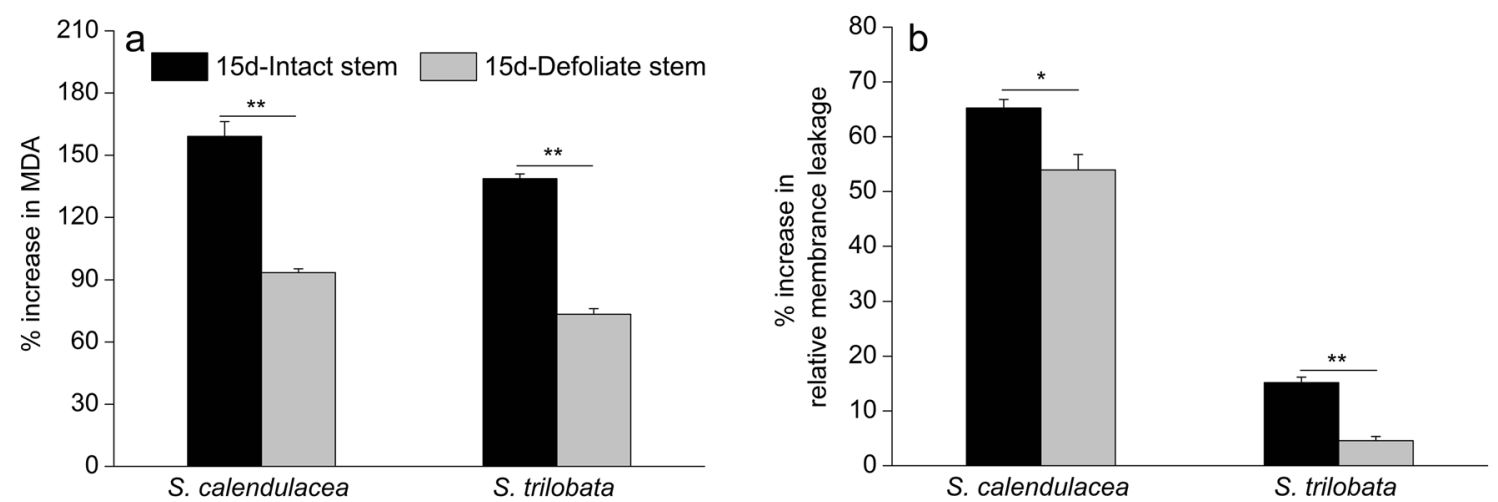

Fig. 7 The \% increase in the properties of cell membranes in intact and defoliated stems of two Sphagneticola species at low temperatures. Panel a represents the \% increase in Malondialdehyde (MDA) in the stems, and Panel $\mathbf{b}$ represents the \% increase in cell membrane leakage in the stems of the two Sphagneticola species after 15-day

low-temperature treatment compared to that at 0 day. *Indicates a significant difference between intact and defoliated stems after lowtemperature treatment $(0.01<p<0.05)$; **Indicates an extremely significant difference between intact and defoliated stems after lowtemperature treatment $(p<0.01)(n=5)$ 


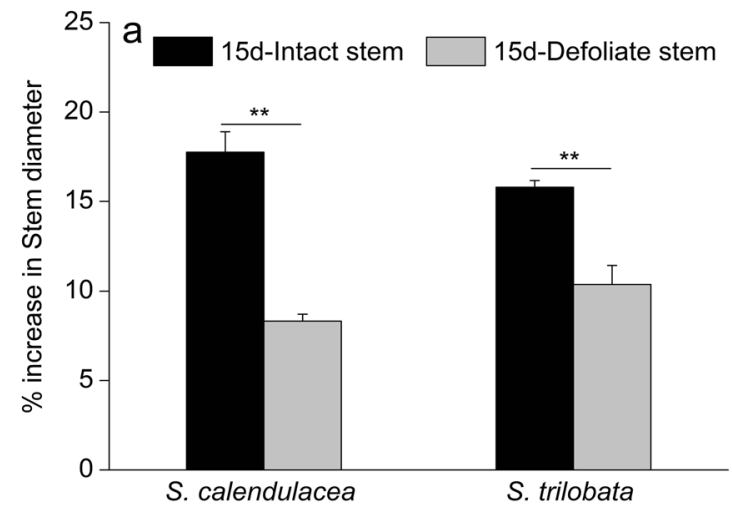

Fig. 8 The \% increase in diameter and biomass in the intact and defoliated stems from two Sphagneticola species at low temperature. Panel a represents the \% increase in the diameter of stems, and Panel b represents the \% increase in the biomass of stems after 15-day lowtemperature treatment compared to that at 0 day. *indicates a signifi-

\section{Discussion}

Leaves are the primary photosynthetic organs, and their phenotypic plasticity has been the focus of most research on the mechanisms by which invasive plants adapt to the external environment. The stem, as a non-photosynthetic organ, also plays a major role in the process of plant invasion, but little research has been performed on its phenotypic plasticity. Since $S$. trilobata is one of the main invasive plants in South China, we used this experimental material as well as a native Sphagneticola species to study the role of the stem in phenotypic plasticity under low temperature, and proposed a regulatory mechanism of the redistribution of energy resources among organs to explain a possible additional mechanism that enhances invasiveness.

\section{Stems of S. trilobata have a stronger tolerance under low temperature}

Temperature is a major factor that limits the normal growth and development of plants. In this study, it was found that the leaves of $S$. calendulacea had stronger low-temperature tolerance than those of $S$. trilobata leaves. The $S$. calendulacea leaves did not show obvious damage, but S. trilobata leaves had large areas of yellowing and low tolerance to low temperature. By contrast, $S$. trilobata stems showed higher tolerance to low temperatures than S. calendulacea (Fig. 1).

The anthocyanin contents in the stems of the two plant species increased significantly under the low-temperature treatment (Fig. 2b). The stem epidermis of $S$. trilobata showed a more obvious increase in reddening than that of S. calendulacea (Fig. 1). Low temperature can cause anthocyanin accumulation, as reported in various studies (Zhang et al. 2019). The production of anthocyanins can attenuate

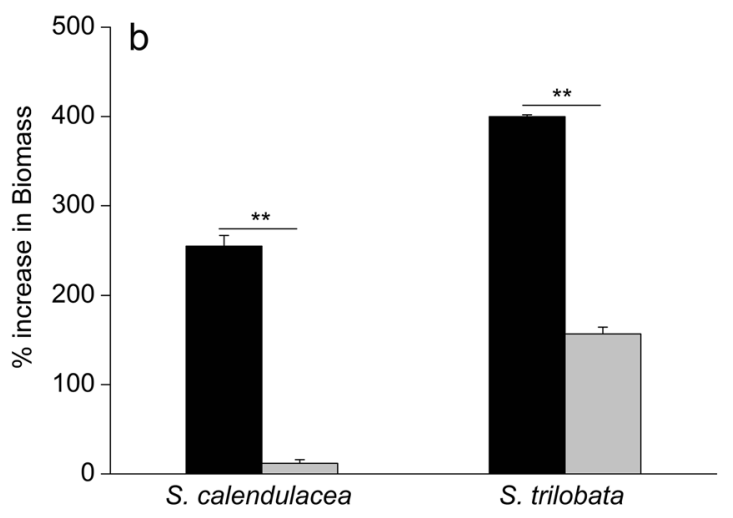

cant difference between intact and defoliated stems after low-temperature treatment $(0.01<p<0.05)$; **indicates an extremely significant difference between intact and defoliated stems after low-temperature treatment $(p<0.01)(n=5)$

external light energy somewhat and can reduce the accumulation of excess light energy (Zhang et al. 2016). Our results indicate that the stem of $S$. trilobata had a greater screening effect on external light energy at low temperatures and could better reduce the accumulation of excess light energy.

In numerous studies, it was found that the increase in anthocyanin content was often accompanied by a decrease in chlorophyll in adverse environmental conditions (Yuan et al. 2013), which prompts the question of whether there is a negative correlation between the two. At present, the literature is unclear on this question, so this phenomenon needs to be studied further. Consistent with the results of previous studies, the photosynthetic pigments, including $\mathrm{Chl} a$, Chl $b$, and $\mathrm{Chl}$, in the stem of $S$. trilobata showed a consistent change trend (Fig. 2d, f, h). The content of photosynthetic pigments in the stem of $S$. trilobata decreased significantly at low temperature, but the decrease was smaller than that in S. calendulacea. This indicated that low temperature might affect photosynthetic pigment synthesis (Glaszmann et al. 1990), but the degree of inhibition of pigment synthesis was lower in S. trilobata than in the native species. Studies have found that chlorophyll fluorescence kinetic parameters can reflect photosynthetic ability of plants (Fu et al. 2012). $F_{\mathrm{v}} / F_{\mathrm{m}}$ is the most commonly used fluorescence parameter, indicating the maximum photochemical efficiency of PSII. When plants are grown in non-adverse conditions, the range of this parameter is generally $0.75-0.85$, but it decreases significantly with adversity or damage (Maxwell and Johnson 2000). The $F_{\mathrm{v}} / F_{\mathrm{m}}$ of the stems of the two Sphagneticola species had the same downward trend, and the decline rate of $S$. calendulacea was larger than that of $S$. trilobata (Fig. 3b). The $\Phi_{\text {PSII }}$ (Fig. 3d) and ETR (Fig. 3f) of the stems exhibited the same decreasing trend as did the $F_{\mathrm{v}} / F_{\mathrm{m}}$. The results indicated that low temperature may damage the photosynthetic 
structure, inhibit photosynthetic electron transport, and lead to a decline in photosynthetic capacity (Ojeda-Pérez et al. 2017).

In general, the decrease in photosynthetic capacity under low temperature leads to excess light energy and the accumulation of ROS (Ksas et al. 2015; Zhang et al. 2012a, b; Lee et al. 2004). Similarly, the results of the tissue localization of ROS showed that the accumulation of superoxide anions (Fig. 4a) and hydrogen peroxide (Fig. 4b) in the stem of $S$. trilobata was lower than that in the native plant stems. It also indicated that the photosynthetic capacity was higher and the extent of photoinhibition was lower in S. trilobata than in the native plant.

Interestingly, the opposite results were found in the leaves of the two plants. At low temperature, the leaves of S. trilobata showed yellowing (Fig. 1), increased anthocyanin content (Fig. 2a), decreased chlorophyll content, and lower external light absorption capacity than that of the native plant (Fig. 2c,e,g), as well as a larger decrease in the chlorophyll fluorescence kinetic parameters of the leaves, including $F_{\mathrm{v}} / F_{\mathrm{m}}, \Phi_{\text {PSII }}$, ETR (Fig. 3a, c, e). These results indicated that the photosynthetic capacity of the leaves of the invasive plants decreased greatly, resulting in serious excess light energy and ROS accumulation in the S. trilobata leaves than in the S. calendulacea leaves (Fig. 4a, b). Therefore, the stress on the leaves of $S$. trilobata was greater than that on the native plant leaves at low temperature. This is consistent with the findings of Wu et al. (2013) that the main distribution areas of $S$. calendulacea were in the temperate zone. Sun et al. (2015) also found that under extremely low-temperature conditions, leaf wilting in S. trilobata was more severe.

ROS in plants exist in a dynamic equilibrium state (Mhamdi and Van Breusegem 2018). Some studies have demonstrated that excessive production of ROS can overwhelm the scavenging system and that antioxidants can effectively scavenge and maintain the balance of ROS (Poljsak et al. 2013; Caverzan et al. 2016). In this study, we found that the increase in antioxidant substances, including flavonoids and total phenols, produced in the stem of $S$. trilobata was greater than that of the native species stem (Fig. 5b, d). The increase in antioxidative substances in the leaves of $S$. trilobata was smaller than that in the native plant (Fig. 5a, c). That is, S. trilobata had a stronger total antioxidant capacity in the stem (Fig. 5f), while S. calendulacea had a stronger total antioxidant capacity in the leaves (Fig. 5e). The differential location of the main antioxidant capacity in the two species also explains the reason that under the same low-temperature conditions, the accumulation of ROS in the stem of $S$. trilobata was small, while that in the leaves of native plant was small. These increased antioxidants could effectively remove the accumulated reactive oxygen species at low temperature.
Therefore, these results indicate that the tolerance of different organs of the same plant to low temperatures will have a combined effect; if the anthocyanin content and antioxidant synthesis of the stem could be increased, the total antioxidant capacity could be improved, the accumulation of reactive oxygen species could be effectively eliminated, and the damage to cell membrane integrity could be reduced in the same plant when the leaves were insufficiently photoprotected. There appears to be a strategy of resource redistribution, which could transfer more newly synthesized resources to the stems for improving the photosynthetic capacity of stems, thereby compensating for the loss of the leaves as photosynthetic organs.

\section{Stem of S. trilobata has a compensatory effect under low temperatures}

At present, many invasive plants have been reported to possess a compensatory mechanism for resource redistribution among different organs (Thapa et al. 2018). Invasive plants are believed to be more regenerative and compensatory than native plants, which is one of the principal reasons for their invasiveness. In this study, a defoliation experiment was used to further verify whether there was a compensatory effect in the stem of $S$. trilobata under low temperature. The results showed that after defoliation, the stem showed reduced anthocyanin synthesis (Fig. 6a) and reduced redness (Fig. 1), but increased chlorophyll content (Fig. 6b, c, d). These changes ensure that $S$. trilobata stem with defoliation could absorb more light for photosynthesis than that of $S$. calendulacea. Therefore, the defoliation treatment caused the stem of S. trilobata to acclimate and acquire a higher photosynthetic compensation capability. Some studies have also shown that the improvement of photosynthesis is a compensatory mechanism in plants and that defoliation can change the photosynthetic status of organs from source to sink and vice versa, thus affecting the possibility of compensatory photosynthesis (Ida et al. 2012).

Compared to that in the intact stem, the degree of oxidative stress in the stem caused by low temperature appears to have been alleviated after defoliation, since the degree of membrane lipid peroxidation (Fig. 7a) and cell membrane leakage decreased (Fig. 7b). This was mainly due to the improvement in the photosynthetic capacity of stems after defoliation. Therefore, the compensatory improvement of the photosynthetic capacity of stems after defoliation was also conducive to the storage of more nutrients in stems, ensuring that the stem diameter (Fig. 8a) and biomass (Fig. 8b) of the two Sphagneticola species increased at low temperature. These results indicated that the stems of the two Sphagneticola species showed a certain photosynthetic compensatory effect that could partly compensate for the loss of the photosynthetic organ leaves after defoliation. The 
stem photosynthetic compensation and resource allocation ability of $S$. trilobata were better than those of $S$. calendulacea. This is also in line with results indicating that invasive plants still produce higher biomass than native plants after defoliation (Burns et al. 2007).

In summary, the resource redistribution between the leaves and stem gives the stem a stronger compensatory effect at low temperatures. This strategy would favor $S$. trilobata, which mainly uses clonal reproduction to maintain normal reproduction throughout the year, accelerating its invasion and affecting its distribution in South China. The stem was more tolerant under low temperatures, which could also promote the invasion of temperate areas by $S$. trilobata.

Acknowledgements We thank all the colleagues in our laboratory for providing useful discussions and technical assistance. We are very grateful to the editor and reviewers for critically evaluating the manuscript and providing constructive comments for its improvement. This work was funded by the National Natural Science Foundation of China (31870374) and the National Key R\&D Program of China (2017YFC1200105). The study was also supported by the Innovation Project of Graduate School of South China Normal University.

Author contributions Minling Cai carried out the experiments, analyzed the data, and the drafted the whole manuscript. Wenqiao Ding and Junjie Zhai participated in the experiments. Wenqiao Ding and Xiaoting Zheng participated in the preparation of the Figures. Zhengchao Yu, Qilei Zhang, and Xiaohua Lin contributed to sample collection. Wah Soon Chow modified the grammar and checked the form of manuscript. Changlian Peng designed the research and experiments.

Data availability All datasets for this study are included in the manuscript and/or the Supplementary Files.

\section{Compliance with ethical standards}

Conflict of interest The authors declare that they have no conflict of interest.

\section{References}

Burns JH, Halpern SL, Winn AA (2007) A test for a cost of opportunism in invasive species in the Commelinaceae. Biol Invasions 9:213-225. https://doi.org/10.1007/s10530-006-9027-3

Caverzan A, Casassola A, Brammer SP (2016) Antioxidant responses of wheat plants under stress. Genet Mol Biol 39:1-6. https://doi. org/10.1590/1678-4685-GMB-2015-0109

Coats VC, Rumpho ME (2014) The rhizosphere microbiota of plant invaders: an overview of recent advances in the microbiomics of invasive plants. Front Microbiol 5:368. https://doi.org/10.3389/ fmicb. 2014.00368

Davidson AM, Jennions M, Nicotra AB (2011) Do invasive species show higher phenotypic plasticity than native species and if so, is it adaptive? A meta-analysis. Ecol Lett 14:419-431. https://doi. org/10.1111/j.1461-0248.2011.01596.x

Early R, Bradley BA, Dukes JS, Lawler JJ, Olden JD, Blumenthal DM et al (2016) Global threats from invasive alien species in the twenty-first century and national response capacities. Nat Commun 7:12485. https://doi.org/10.1038/ncomms12485

Ellouzi H, Ben HK, Cela J, Munné-Bosch S, Abdelly C (2011) Early effects of salt stress on the physiological and oxidative status of Cakile maritima (halophyte) and Arabidopsis thaliana (glycophyte). Physiol Plant 142:128-143. https://doi.org/10.111 $1 / \mathrm{j} .1399-3054.2011 .01450 . \mathrm{x}$

Feild TS, Lee DW, Holbrook NM (2001) Why leaves turn red in autumn. The role of anthocyanins in senescing leaves of red-osier dogwood. Plant Physiol 127:566-574. https://doi. org/10.2307/4280112

Fu W, Li P, Wu Y (2012) Effects of different light intensities on chlorophyll fluorescence characteristics and yield in lettuce. Sci Hortic 135:45-51. https://doi.org/10.1016/j.scienta.2011.12.004

Fusco G, Minelli A (2010) Phenotypic plasticity in development and evolution: facts and concepts. Philos Trans R Soc B 365:547556. https://doi.org/10.1098/rstb.2009.0267

Gard B, Bretagnolle F, Dessaint F et al (2013) Invasive and native populations of common ragweed exhibit strong tolerance to foliar damage. Basic Appl Ecol 14:28-35. https://doi. org/10.1016/j.baae.2012.10.007

Genty B, Briantais JM, Baker NR (1989) The relationship between the quantum yield of photosynthetic electron transport and quenching of chlorophyll fluorescence. Biochim Biophys Acta 990:87-92. https://doi.org/10.1016/S0304-4165(89)80016-9

Gioria M, Osborne BA (2014) Resource competition in plant invasions: emerging patterns and research needs. Front Plant Sci 5:501. https://doi.org/10.3389/fpls.2014.00501

Glaszmann JC, Kaw RN, Khush GS (1990) Genetic divergence among cold tolerant rices (Oryza sativa L). Euphytica 45:95104. https://doi.org/10.1007/BF00033276

Gratani L (2014) Plant phenotypic plasticity in response to environmental factors. Adv Bot 2014:1-17. https://doi. org/10.1155/2014/208747

Hoffmann BD, Courchamp F (2016) Biological invasions and natural colonisations: are they that different? NeoBiota 29:1-14. https ://doi.org/10.3897/neobiota.29.6959

Huang QQ, Wu JM, Bai YY, Zhou L, Wang GX (2009) Identifying the most noxious invasive plants in China: role of geographical origin, life form and means of introduction. Biodivers Conserv 18:305-316. https://doi.org/10.1007/s10531-008-9485-2

Ida TY, Harder LD, Kudo G (2012) Effects of defoliation and shading on the physiological cost of reproduction in silky locoweed Oxytropis sericea. Ann Bot 109:237-246. https://doi. org/10.1093/aob/mcr273

Ksas B, Becuwe N, Chevalier A, Havaux M (2015) Plant tolerance to excess light energy and photooxidative damage relies on plastoquinone biosynthesis. Sci Rep 5:10919. https://doi.org/10.1038/ srep10919

Lee SH, Singh AP, Chung GC (2004) Rapid accumulation of hydrogen peroxide in cucumber roots due to exposure to low temperature appears to mediate decreases in water transport. J Exp Bot 55:1733-1741. https://doi.org/10.1093/jxb/erh189

Li J, Xiao T, Zhang Q, Dong M (2013) Interactive effect of herbivory and competition on the invasive plant Mikania micrantha. PLoS ONE 8:e62608. https://doi.org/10.1371/journal.pone.0062608

Liu YT, Dai ZC, Xue TL et al (2013) Prediction of suitable area of an alien invasive species (Wedelia trilobata) in China. Guangdong Agric Sci 40:174-178. https://doi.org/10.3969/j. issn.1004-874X.2013.14.053

Liu YH, Offler CE, Ruan YL (2014) A simple, rapid, and reliable protocol to localize hydrogen peroxide in large plant organs by DAB-mediated tissue printing. Front Plant Sci 5:745. https:// doi.org/10.3389/fpls.2014.00745 
Loeser MR, Crews TE, Sisk TD (2004) Defoliation increased aboveground productivity in a semi-arid grassland. J Range Manag 57:442-447. https://doi.org/10.2307/4003972

Maxwell K, Johnson GN (2000) Chlorophyll fluorescence-a practical guide. J Exp Bot 51:659-668. https://doi.org/10.1093/jexbo $\mathrm{t} / 51.345 .659$

Mhamdi A, Van Breusegem F (2018) Reactive oxygen species in plant development. Development. https://doi.org/10.1242/dev.164376

Murren CJ, Auld JR, Callahan H et al (2015) Constraints on the evolution of phenotypic plasticity: limits and costs of phenotype and plasticity. Heredity 115:293-301. https://doi.org/10.1038/ hdy. 2015.8

Ojeda-Pérez ZZ, Jiménez-Bremont JF, Delgado-Sánchez P et al (2017) Continuous high and low temperature induced a decrease of photosynthetic activity and changes in the diurnal fluctuations of organic acids in Opuntia streptacantha. PLoS ONE 12:e0186540. https://doi.org/10.1371/journal.pone.0186540

Oxborough K, Baker NR (1997) Resolving chlorophyll a fluorescence images of photosynthetic efficiency into photochemical and nonphotochemical components-calculation of qP and $F_{v}{ }^{\prime} / F_{m}$ without measuring $F_{0}{ }^{\prime}$. Photosynth Res 54:135-142. https://doi. org/10.1023/A:1005936823310

Poljsak B, Suput D, Milisav I (2013) Achieving the balance between ROS and antioxidants: when to use the synthetic antioxidants. Oxid Med Cell Longev 2013:956792. https://doi. org/10.1155/2013/956792

Shen S, Xu G, Clements DR, Jin G, Liu S, Yang Y, Chen A, Zhang F, Kato-Noguchi H (2016) Suppression of reproductive characteristics of the invasive plant Mikania micrantha by sweet potato competition. BMC Ecol 16:30. https://doi.org/10.1186/s1289 8-016-0085-9

Sim CH, Woo KJ, Cha Y, Kim C (2006) A quantitative nitroblue tetrazolium assay for determining intracellular superoxide anion production in phagocytic cells. J Immunoass Immunochem 27:31-44. https://doi.org/10.1080/15321810500403722

Soengas P, Rodriguez VM, Velasco P, Cartea ME (2018) Effect of temperature stress on antioxidant defenses in Brassica oleracea. ACS Omega 3:5237-5243. https://doi.org/10.1021/acsomega.8b00242

Song LY, Sun LL, Shu Z, Zeng W, Li WH, Peng CL (2009) Effects of drought stress and rehydration on chlorophyll fluorescence characteristics in leaves of invasive Wedelia trilobata. Acta Ecol Sin 29:3713-3721. https://doi.org/10.3321/j. issn: 1000-0933.2009.07.032

Song LY, Li CH, Peng SL (2010) Elevated $\mathrm{CO}_{2}$ increases energy-use efficiency of invasive Wedelia trilobata over its indigenous congener. Biol Invasions 12:1221-1230. https://doi.org/10.1007/s1053 0-009-9541-1

Sun ZY, Chen YQ, Schaefer V, Liang HM, Li WH, Huang SQ, Peng CL (2015) Responses of the Hybrid between Sphagneticola trilobata and Sphagneticola calendulacea to low temperature and weak light characteristic in south China. Sci Rep 5:16906. https ://doi.org/10.1038/srep16906

Takao LK, Ribeiro JPN, Lima MIS (2011) Allelopathic effects of Ipomoea cairica (L.) Sweet on crop weeds. Acta Bot Bras 25:858864. https://doi.org/10.1590/S0102-33062011000400012

Thapa S, Chitale V, Rijal SJ, Bisht N, Shrestha BB (2018) Understanding the dynamics in distribution of invasive alien plant species under predicted climate change in Western Himalaya. PLoS ONE 13:e0195752. https://doi.org/10.1371/journal.pone.0195752

Tuller J, Marquis RJ, Andrade SMM, Monteiro AB, Faria LDB (2018) Trade-offs between growth, reproduction and defense in response to resource availability manipulations. PLoS ONE 13:e0201873. https://doi.org/10.1371/journal.pone.0201873

Wang ZM, Wei AL, Zheng DM (2001) Photosynthetic characteristics of non-leaf organs of winter wheat cultivars differing in ear type and their relationship with grain mass per ear. Photosynthetica 39:239-244. https://doi.org/10.1023/A:1013743523029

Wang BS, Liao WB, Zan QJ, Li MG, Zhou XY, Gao SH (2003) The spreads of Mikania micrantha in China. Acta Sci Nat Univ Sunyatseni 42:47-50. https://doi.org/10.3321/j. issn:0529-6579.2003.04.014

Wang LL, Wang B, Shang N, Liu WZ (2016) Effects of experimental defoliation on resource allocation using integrated physiological units in the andromonoecious Camptotheca acuminata. S Afr J Bot 104:47-54. https://doi.org/10.1016/j.sajb.2015.11.007

Wellburn AR (1994) The spectral determination of chlorophylls $a$ and $b$, as well as total carotenoids, using various solvents with spectrophotometers of different resolution. J Plant Physiol 144:307-313. https://doi.org/10.1016/S0176-1617(11)81192-2

Wu W, Zhou RS, Ni GY, Shen H, Ge XJ (2013) Is a new invasive herb emerging? Molecular confirmation and preliminary evaluation of natural hybridization between the invasive Sphagneticola trilobata (Asteraceae) and its native congener $S$. calendulacea in south China. Biol Invasions 15:75-88. https://doi.org/10.1007/ s10530-012-0269-y

Xiao Y, Dean AM (2016) Phenotypic plasticity as an adaptation to a functional trade-off. Elife 5:e19307. https://doi.org/10.7554/eLife .19307

Xu DP, Li Y, Meng X, Zhou T, Zhou Y, Zheng J, Zhang JJ, Li HB (2017) Natural antioxidants in foods and medicinal plants: extraction, assessment and resources. Int J Mol Sci 18:96. https://doi. org/10.3390/ijms 18010096

Yang FJ, He HS, Wang WJ et al (2006) Different characteristics of photosynthesis in stems and leaves of Mikania micranth. J Plant Ecol 6:998-1004. https://doi.org/10.17521/cjpe.2006.0128

Yuan Y, Wang B, Zhang S, Tang J, Tu C, Hu S et al (2013) Enhanced allelopathy and competitive ability of invasive plant Solidago canadensis in its introduced range. J Plant Ecol 6:253-263. https ://doi.org/10.1093/jpe/rts033

Zhang JZ, Zhang QL, Chen YJ, Sun LL, Song LY, Peng CL (2012a) Improved tolerance toward low temperature in banana (Musa AAA Group Cavendish Williams). S Afr J Bot 78:290-294. https ://doi.org/10.1016/j.sajb.2011.08.002

Zhang QL, Su LJ, Chen JW, Zeng XQ, Sun BY, Peng CL (2012b) The antioxidative role of anthocyanins in Arabidopsis under highirradiance. Biol Plant 56:97-104. https://doi.org/10.1007/s1053 5-012-0022-5

Zhang TJ, Chow WS, Liu X, Zhang P, Liu N, Peng CL (2016) A magic red coat on the surface of young leaves: anthocyanins distributed in trichome layer protect Castanopsis fissa leaves from photoinhibition. Tree Physiol 36:1296. https://doi.org/10.1093/treephys/ tpw080

Zhang QL, Zhai JJ, Shao L, Lin W, Peng CL (2019) Accumulation of anthocyanins: an adaptation strategy of Mikania micrantha to low temperature in winter. Front Plant Sci 10:1049. https://doi. org/10.3389/fpls.2019.01049

Publisher's Note Springer Nature remains neutral with regard to jurisdictional claims in published maps and institutional affiliations. 